\title{
Differentially expressed genes in Mycobacterium tuberculosis H37Rv under mild acidic and hypoxic conditions
}

\author{
Correspondence \\ Jeong-Kyu Park \\ jekpark@cnu.ac.kr \\ or \\ Sung Jae Shin \\ sjshin@cnu.ac.kr
}

Received 27 February 2008

Accepted 21 August 2008

\author{
Su-Young Kim, ${ }^{1,2}$ Byung-Soo Lee, ${ }^{1}$ Sung Jae Shin, ${ }^{1,2}$ Hwa-Jung Kim ${ }^{1}$ \\ and Jeong-Kyu Park ${ }^{1,3}$
}
${ }^{1}$ Department of Microbiology, College of Medicine, Chungnam National University, Daejeon 301 - 747, Republic of Korea
${ }^{2}$ Infectious Signaling Network Research Center, College of Medicine, Chungnam National University, Daejeon 301-747, Republic of Korea
${ }^{3}$ Cancer Research Institute, College of Medicine, Chungnam National University, Daejeon 301-747, Republic of Korea

\begin{abstract}
The survival mechanism of dormant tubercle bacilli is unknown; however, accumulating evidence indicates that Mycobacterium tuberculosis can survive and persist in hypoxic and mildly acidic microenvironments. Such conditions are found in the acidic vacuoles of macrophages, which $M$. tuberculosis is known to target. We used DECAL (differential expression using customized amplification library) to identify the genes expressed under acidic and hypoxic conditions, following the cultivation of $M$. tuberculosis $\mathrm{H} 37 \mathrm{Rv}$ at an acidic $\mathrm{pH}$ and/or under hypoxic or anoxic conditions in vitro. Of 960 clones analysed, 144 genes, consisting of 71 induced and 8 repressed genes, were identified by sequencing and divided into functional categories to characterize their cellular roles. In general, the genes induced under acidic and hypoxic conditions were involved in the biosynthesis of secondary metabolites (e.g. pks4), lipid metabolism, energy production (e.g. pckA) and cell wall biogenesis (e.g. Rv0696 and p/cB). The combination of genes identified may explain the energy processing and energy storage of $M$. tuberculosis during latent infection. These findings not only enhance our understanding of the mechanism of dormancy, but they also may be useful in the design of therapeutic tools and vaccines for latent tuberculosis.
\end{abstract}

\section{INTRODUCTION}

Tuberculosis (TB) is a major cause of morbidity worldwide. A recent survey estimated that one third of the world's population is infected with tubercle bacilli, and that around 3000 deaths occur annually due to TB in Korea (Mustafa Abu \& Al-Attiyah, 2003); however, most individuals infected with Mycobacterium tuberculosis do not progress to active disease. Nevertheless, approximately $10 \%$ of infected individuals develop reactivated TB during their lifetime (Kochi, 1991). Current TB chemotherapy involves bactericidal agents, which target actively growing bacteria; however, they do not eliminate latent or dormant bacteria persisting inside the host.

A bacillus may remain in its host for decades in a dormant state, meaning that an infected individual carries the potential

Abbreviations: CAL, customized amplification library; DECAL, differential expression using customized amplification library; TB, tuberculosis.

Tables of primer sequences and expression data are available as supplementary material with the online version of this paper. for revival or reactivation of the disease (Wayne, 1994). Dormancy is characterized by nonreplication persistence (NRP) resulting from the presence of metabolically inactive organisms. Important factors to consider in terms of the initiation of NRP include nutrient depletion, shifts in $\mathrm{pH}$, the production of specific growth-limiting products and oxygen depletion (Wayne \& Hayes, 1996). Dormant tubercle bacilli exist in granulomas in mildly acidic and hypoxic microenvironments (Koul et al., 2004; Russell, 2001; Salkin \& Wayne, 1956). However, the survival mechanism of dormant mycobacteria and the reactivation mechanism of TB are unknown.

Wayne and colleagues developed an in vitro culture system to study mycobacterial dormancy and confirmed that oxygen depletion is a critical signal that triggers the dormancy response in bacilli (Wayne, 1994; Wayne \& Hayes, 1996). Mycobacteria inhibit phagosome maturation by blocking the fusion of phagosomes with early endosomes and lysosomes, and by causing alterations in membrane proteins that normally promote the formation of an acidic phagolysosome (Koul et al., 2004). 
The DECAL (differential expression using customized amplification library) method extends the applicability of DNA arrays to situations in which limited amounts of initial RNA are available (Alland et al., 1998). Moreover, once a customized amplification library (CAL) is prepared, it may be used repeatedly.

Here, we analysed the genes that are induced or repressed in M. tuberculosis strain $\mathrm{H} 37 \mathrm{Rv}$ under mildly acidic and hypoxic conditions in vitro using DECAL and sequence analysis. In addition, the functional roles of the genes were examined with regard to energy processing in a dormant state.

\section{METHODS}

Construction of the plasmid library. The M. tuberculosis H37Rv library was constructed in pBluescript II SK ${ }^{-}$(Stratagene) using genomic DNA isolated from M. tuberculosis H37Rv as described by Belisle \& Sonnenberg (1998) and Sambrook \& Russel (2001). The DNA was partially restricted with BamHI. pBluescript II SK ${ }^{-}$was prepared by digestion with BamHI and then dephosphorylated with calf intestinal alkaline phosphatase. The plasmid DNA was then ligated with the genomic fragments. The resulting recombinant plasmids were used to transform Escherichia coli DH-5 $\alpha$ competent cells and ampicillin resistance was selected for on solid Luria-Bertani plates containing X-Gal and IPTG.

CAL production. The M. tuberculosis $\mathrm{H} 37 \mathrm{Rv}$ CAL was constructed as described by Alland et al. (1998), with several modifications. Identification of the clones containing rRNA (5S, 16S and 23S) genes was achieved by dot blot hybridization and amplified by PCR with Uniamp primers. The amplification included a $5 \mathrm{~min}$ hot start followed by ten cycles of 1 min segments at 95, 65 and $72{ }^{\circ} \mathrm{C}$. After the end of the tenth cycle, $4 \mathrm{U}$ fresh Taq DNA polymerase was added, and 27 additional cycles were performed at $95{ }^{\circ} \mathrm{C}$ for $1 \mathrm{~min}, 65^{\circ} \mathrm{C}$ for $2 \mathrm{~min}$ and $72{ }^{\circ} \mathrm{C}$ for $3 \mathrm{~min}$. The sequences of the primers used are listed in Supplementary Table S1, available with the online journal. Plasmid DNA from the library was extracted and transferred onto a positively charged nylon membrane (Schleicher \& Schuell). The PCRamplified rRNA genes were then labelled and hybridized using a DIG non-radioactive nucleic acid labelling and detection system (Boehringer Mannheim) and dot blots. DNA from the negative clones was pooled and digested with BamHI. The inserts from the digested DNA were purified from agarose gels with a QIAEX II agarose gel extraction kit (Qiagen). The purified DNA was then digested with $A l u \mathrm{I}$, and the section corresponding to 400-1500 bp was extracted. The purified DNA was then ligated with Uniamp XhoI adapters

Culture conditions and RNA extraction procedure. M. tuberculosis $\mathrm{H} 37 \mathrm{Rv}$ was grown in minimal Sauton medium as surface pellicles. The medium was then removed by filtration and the bacterial cells were transferred to a $0.2 \mu \mathrm{m}$ vent-cap flask (Corning) containing normal ( $\mathrm{pH} 7.2$ ) or mildly acidic $7 \mathrm{H} 9$ medium (pH 6.0). The bacilli were cultured static for 8 days at $37{ }^{\circ} \mathrm{C}$ in a $\mathrm{CO}_{2}$ incubator set at 21 or $13 \% \mathrm{O}_{2}$, or in an anaerobic jar (Oxoid) containing AnaeroGen (Oxoid) and an anaerobic indicator (Oxoid): normal conditions ( $\mathrm{pH} 7.2$ and $21 \% \mathrm{O}_{2}$ ), normal $\mathrm{pH}$ with hypoxia $\left(\mathrm{pH} 7.2\right.$ and $\left.13 \% \mathrm{O}_{2}\right)$, normal $\mathrm{pH}$ with anoxia ( $\mathrm{pH} 7.2$ and $0 \% \mathrm{O}_{2}$ ), mildly acidic $\mathrm{pH}$ with hypoxia $(\mathrm{pH} 6.0$ and $\left.13 \% \mathrm{O}_{2}\right)$, and mildly acidic $\mathrm{pH}$ with anoxia $\left(\mathrm{pH} 6.0\right.$ and $0 \% \mathrm{O}_{2}$ ). The media were buffered with $100 \mathrm{mM}$ MOPS and adjusted to $\mathrm{pH}$ 6.0. The culture turbidity $\left(\mathrm{OD}_{540}\right)$ of $M$. tuberculosis under these five conditions was measured. Steady-state growth was identified by monitoring the cultures for constant turbidity. After 8 days, tubercle bacilli had reached steady state growth under each condition. Total RNA from M. tuberculosis H37Rv grown under the above conditions was isolated using a Catrimox-14 RNA isolation kit (Takara), according to the manufacturer's instructions and a published protocol (Payton \& Pinter, 1999). Briefly, the bacterial cells were pelleted, resuspended in Catrimox-14 and sonicated on ice. The cell lysate was then vortexed for $1 \mathrm{~min}$ and allowed to form micelles. The lysate was then centrifuged, and the pellet was resuspended in guanidine solution (4 M guanidine isothiocyanate, $0.2 \mathrm{M}$ sodium acetate, $\mathrm{pH} 4.0$ ). The suspension was treated with RNase-free DNase at a final concentration of $2 \mu \mathrm{g} \mathrm{ml}^{-1}$, incubated for $60 \mathrm{~min}$ at $37{ }^{\circ} \mathrm{C}$ and extracted with phenol/chloroform/isoamyl alcohol. The aqueous layer was precipitated in 2-propanol, washed with $70 \%$ ethanol and air dried. The RNA pellet was then resuspended in diethylpyrocarbonate-treated water and examined by gel electrophoresis.

Probe construction. The RNA was reverse transcribed with biotinlabelled random hexamers and biotin-dATP using SuperScript II (Gibco-BRL) at $50{ }^{\circ} \mathrm{C}$ for $1 \mathrm{~h}$; RNase $\mathrm{H}$ was subsequently added for $30 \mathrm{~min}$ at $37{ }^{\circ} \mathrm{C}$. Next, $300 \mathrm{ng}$ CAL, $20 \mu \mathrm{g}$ salmon sperm DNA and 20 $\mu \mathrm{g}$ tRNA were added to the cDNA in a final volume of $150 \mu \mathrm{l}$. The sample was then extracted with phenol/chloroform, ethanol-precipitated overnight, resuspended in $6 \mu \mathrm{l} 3 \mathrm{mM}$ EDTA containing $30 \mathrm{mM}$ HEPPS (pH 8.0; Sigma), overlain with oil, and heated to $99{ }^{\circ} \mathrm{C}$ for $5 \mathrm{~min}$; thereafter, $1.5 \mu \mathrm{l} \mathrm{M} \mathrm{NaCl}$ preheated to $69{ }^{\circ} \mathrm{C}$ was added. The sample was then incubated at $69^{\circ} \mathrm{C}$ for 3 to 4 days, then diluted with $150 \mu \mathrm{l}$ incubation buffer $(1 \times \mathrm{TE}, 1 \mathrm{M} \mathrm{NaCl}$ and $0.5 \%$ Tween 20) preheated to $69^{\circ} \mathrm{C}$ and $50 \mu$ l washed, preheated streptavidin-coated magnetic beads (Roche Diagnostics) were added. The sample was incubated at $55{ }^{\circ} \mathrm{C}$ with occasional mixing for $30 \mathrm{~min}$, and washed three times at room temperature and three times for $30 \mathrm{~min}$ at $69^{\circ} \mathrm{C}$ with $0.1 \%$ SDS and $0.2 \times$ SSC by placing the microcentrifuge tubes on a hybridization shaker. The sample was then washed with $2.5 \mathrm{mM}$ EDTA and eluted by boiling in $80 \mu \mathrm{l}$ water. PCR was performed as described for CAL preparation using $20 \mu \mathrm{l}$ sample in each reaction.

Screening. The plasmid library arrays were prepared using a Bio-Dot apparatus (Bio-Rad) by double-spotting the plasmid clones onto a nylon membrane. The PCR probes were labelled with $\left[\alpha-{ }^{32} \mathrm{P}\right] \mathrm{dCTP}$ using a DNA-labeller probe DNA labelling kit (Intron). Unincorporated radiolabelled nucleotides were removed by passing the solution through a probe DNA purifying system (Intron) and hybridized to dot blots for $16-18 \mathrm{~h}$ as described elsewhere (Sambrook \& Russel, 2001). The blots were then washed twice at room temperature for $15 \mathrm{~min}$ each in $2 \times \mathrm{SSC}$ and $0.1 \% \mathrm{SDS}$, and at $68{ }^{\circ} \mathrm{C}$ for $30 \mathrm{~min}$ each in $0.1 \times$ SSC and $0.1 \%$ SDS. The spot density of dot blot hybridization was analysed using ArrayGauge (Fujifilm) software. The background was subtracted from the value of each spot on the array. The calculated numeric data were transformed and revealed coloured spots according to each standard. Based on normal conditions ( $\mathrm{pH} 7.2$ and aerobic), the fold change was calculated. The clones that hybridized at different intensities with the two probes were selected for further analysis.

Sequencing of the differentially expressed clones. The clones were sequenced using an ABI PRISM BigDye terminator cycle sequencing ready reaction kit (Applied Biosystems) and an ABI PRISM 310 Genetic Analyzer (Applied Biosystems). For each clone, the start and end sequences of the inserts were generated using a T7 primer, which annealed to either side of the multiple cloning site in pBluescript II SK ${ }^{-}$. A BLAST search was conducted to identify matches to the M. tuberculosis H37Rv sequences deposited in the National 
Center for Biotechnology Information database (www.ncbi.nlm. nih.gov) by allowing the size and content of each insert to be extrapolated.

Confirmation of the genes by RT-PCR. Representative induced and repressed genes were randomly chosen to confirm their fold changes by RT-PCR. Briefly, cDNA was obtained from the total RNA with reverse transcriptase and random primers at $42{ }^{\circ} \mathrm{C}$ for $60 \mathrm{~min}$. The reactions were stopped by heat inactivation for $5 \mathrm{~min}$ at $95{ }^{\circ} \mathrm{C}$ and chilled on ice. The cDNA was then amplified by PCR. The sequences of the primers used for amplification are shown in Supplementary Table S1, available with the online journal. The amplification consisted of 30 cycles of $1 \mathrm{~min}$ at $95{ }^{\circ} \mathrm{C}, 1 \mathrm{~min}$ at $50{ }^{\circ} \mathrm{C}$ and $1 \mathrm{~min}$ at $72{ }^{\circ} \mathrm{C}$. The $r p o B$ was used as an internal control. The products were then subjected to $1 \%$ agarose gel electrophoresis and the intensity of each band was calculated using Quantity One software (version 4.1.0; Bio-Rad). All samples were compared to normal culture (oxygen pressure of $21 \%, \mathrm{pH} 7.2$; condition 1) and the gene expression level of this condition corresponds to 1 . The RT-PCR results were expressed as the fold induction relative to the control value of normal culture.

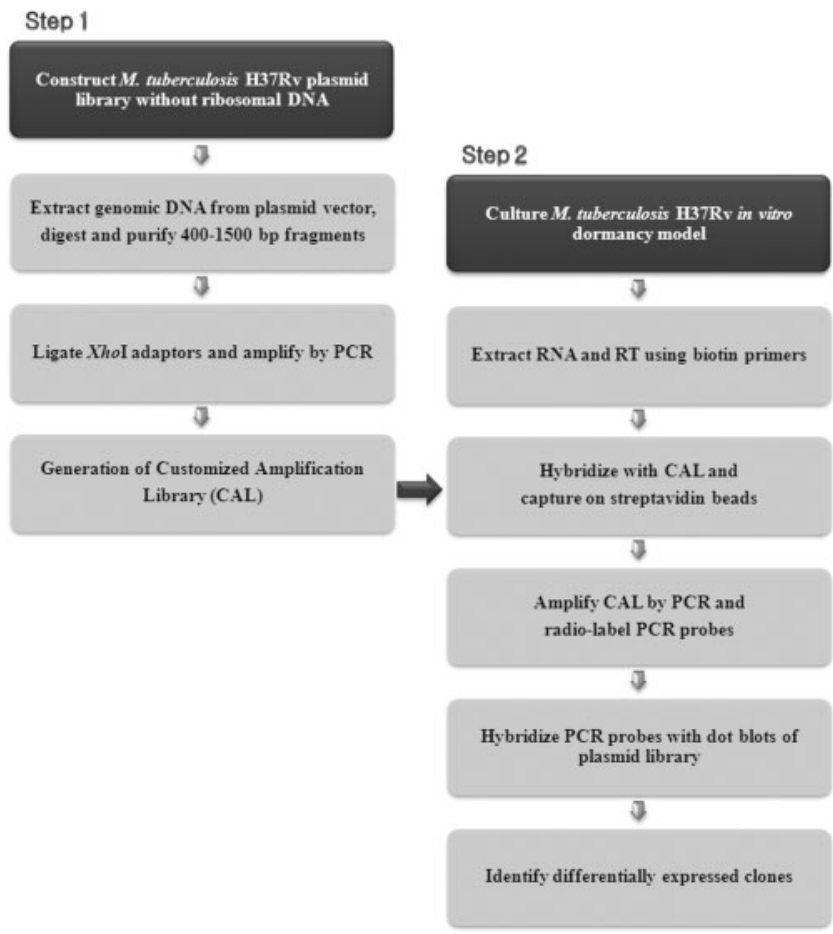

Fig. 1. Schematic of the steps in the use of DECAL for $M$. tuberculosis H37Rv. A plasmid library was screened for clones containing rDNA. Non-ribosomal plasmids were extracted, digested and purified to generate smaller and similar-sized fragments. These fragments were ligated to Xhol adaptors and PCR amplified. Total RNA was isolated from mycobacteria cultured under different conditions, reverse-transcribed using biotin-labelled random primers and hybridized to the CAL. The captured CAL was amplified to generate PCR probes, radiolabelled and hybridized with dot blots of the plasmid library. Differentially expressed spots were selected and identified.

\section{RESULTS AND DISCUSSION}

\section{Generation of M. tuberculosis H37Rv CAL and probe}

We applied DECAL to identify induced or repressed genes in $M$. tuberculosis under mild acidic and hypoxic conditions (Fig. 1). To generate a CAL for the M. tuberculosis H37Rv genome, genomic DNA from a plasmid library was extracted and digested. The fragments were then ligated to adapters and amplified by PCR (Fig. 1, step 1). The CAL was then used for optimal and efficient amplification of the mRNAs expressed under different conditions.

M. tuberculosis can successfully adapt to hypoxia in vitro, and the growth of mycobacteria under acidic conditions (a)

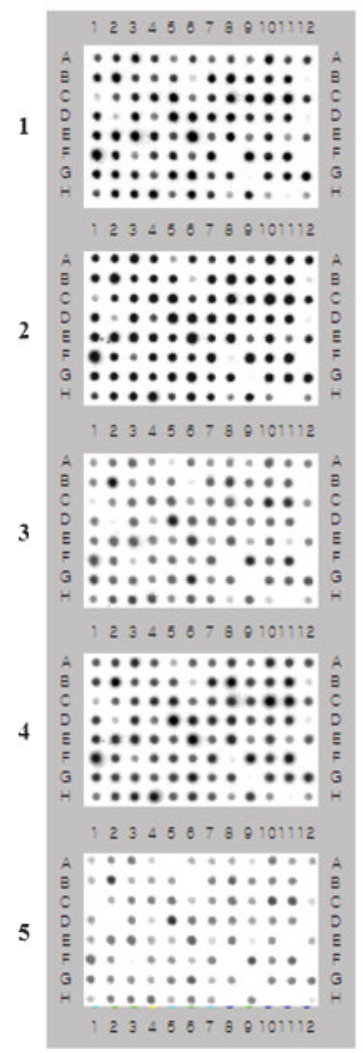

(b)

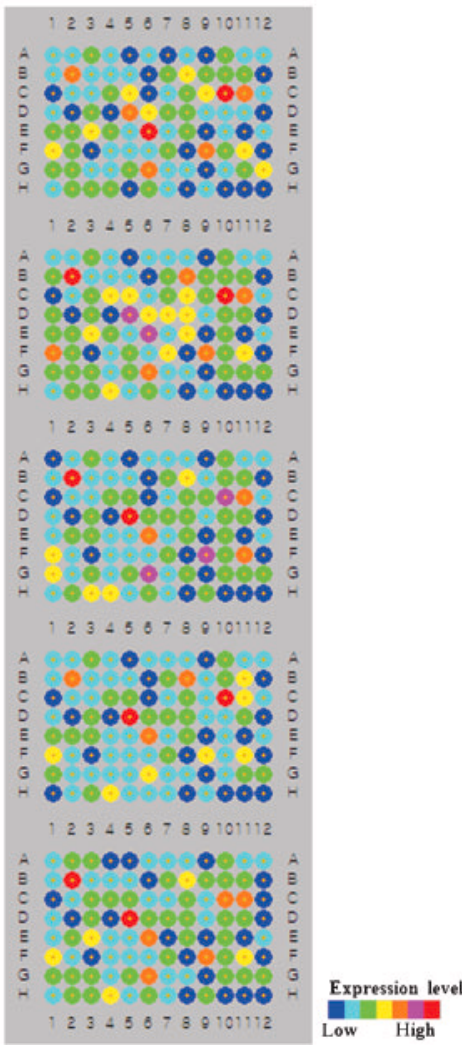

Fig. 2. Spot density of dot blot hybridization with PCR probes to the M. tuberculosis H37Rv plasmid library. Dot blots were hybridized with radiolabelled PCR probes for each of the following conditions: (1) normal conditions ( $\mathrm{pH} 7.2$ and $\left.21 \% \mathrm{O}_{2}\right),(2)$ normal $\mathrm{pH}$ with hypoxia $\left(\mathrm{pH} 7.2\right.$ and $13 \% \mathrm{O}_{2}$ ), (3) normal $\mathrm{pH}$ with anoxia ( $\mathrm{pH} 7.2$ and $0 \% \mathrm{O}_{2}$ ), (4) mildly acidic $\mathrm{pH}$ with hypoxia $\left(\mathrm{pH} 6.0\right.$ and $\left.13 \% \mathrm{O}_{2}\right)$, (5) mildly acidic $\mathrm{pH}$ with anoxia $(\mathrm{pH} 6.0$ and $0 \% \mathrm{O}_{2}$ ). The original results of dot blot hybridization are shown in (a). The results were then analysed using ArrayGauge software. Spot density is indicated by colour. The highest and lowest levels of expression are represented by red and blue, respectively (b). 
Table 1. M. tuberculosis H37Rv genes with increased expression under mild acidic and hypoxic conditions

\begin{tabular}{|c|c|c|c|}
\hline Locus & Annotated gene & Product & Fold change \\
\hline Rv0017c & $\operatorname{rod} A$ & Probable cell division protein & 1.8 \\
\hline $\mathrm{Rv0107c}$ & $\operatorname{ctpI}$ & Probable cation-transporter ATPase & 2.3 \\
\hline Rv0108c & & Hypothetical protein & 2.3 \\
\hline Rv0109 & PE_PGRS1 & PE-PGRS family protein & 2.0 \\
\hline Rv0211 & pckA & Probable iron-regulated phosphoenolpyruvate carboxykinase & 2.1 \\
\hline Rv0212c & $\operatorname{nadR}$ & Possible transcriptional regulatory protein & 2.1 \\
\hline Rv0247c & & Probable succinate dehydrogenase & 1.6 \\
\hline Rv0248c & & Probable succinate dehydrogenase & 1.6 \\
\hline Rv0285 & PE5 & PE family protein & 1.6 \\
\hline Rv0286 & PPE4 & PPE family protein & 1.6 \\
\hline Rv0312 & & Conserved hypothetical proline- and threonine-rich protein & 1.6 \\
\hline Rv0477 & & Possible conserved secreted protein & 1.7 \\
\hline Rv0478 & deoC & Probable deoxyribose-phosphate aldolase & 1.7 \\
\hline Rv0508 & & Conserved hypothetical protein & 2.1 \\
\hline Rv0509 & hemA & Probable glutamyl-tRNA reductase & 2.1 \\
\hline Rv0510 & hemC & Probable porphobilinogen deaminase & 1.6 \\
\hline Rv0554 & bpoC & Possible peroxidase & 1.8 \\
\hline Rv0695 & & Conserved hypothetical protein & 2.3 \\
\hline Rv0696 & & Probable membrane sugar transferase & 2.6 \\
\hline Rv0983 & pepD & Probable serine protease & 1.7 \\
\hline Rv0984 & moaB2 & Possible pterin- $4-\alpha$-carbinolamine dehydratase & 1.7 \\
\hline Rv1064c & $l p q V$ & Possible lipoprotein & 1.6 \\
\hline Rv1065 & & Conserved hypothetical protein & 1.6 \\
\hline Rv1071c & echA9 & Possible enoyl-coA hydratase & 1.8 \\
\hline Rv1140 & & Probable integral membrane protein & 1.5 \\
\hline Rv1141c & echA11 & Probable enoyl-coA hydratase & 1.5 \\
\hline Rv1162 & narH & Probable respiratory nitrate reductase & 1.7 \\
\hline Rv1181 & $p k s 4$ & Polyketide $\beta$-ketoacyl synthase & 3.8 \\
\hline Rv1262c & & Hypothetical HIT-like protein & 1.7 \\
\hline Rv1263 & amiB2 & Probable amidase & 1.7 \\
\hline Rv1524 & & Probable glycosyltransferase & 1.9 \\
\hline Rv1604 & $i m p A$ & Probable inositol-monophosphatase & 1.7 \\
\hline Rv1605 & hisF & Probable cyclase & 1.7 \\
\hline Rv1759c & wag22 & PE-PGRS family protein & 2.0 \\
\hline Rv1857 & $\bmod A$ & Probable molybdate-binding lipoprotein & 1.6 \\
\hline Rv1858 & $\bmod B$ & Probable molbdenum-transport integral membrane protein & 1.6 \\
\hline Rv2041c & & Probable sugar-binding lipoprotein & 1.9 \\
\hline Rv2042c & & Hypothetical protein & 1.9 \\
\hline Rv2199c & & Possible conserved integral membrane protein & 1.8 \\
\hline Rv2200c & $c t a C$ & Probable transmembrane cytochrome $\mathrm{C}$ oxidase & 1.8 \\
\hline $\operatorname{Rv} 2258 c$ & & Possible transcriptional regulatory protein & 1.6 \\
\hline Rv2259 & adhE2 & Probable zinc-dependent alcohol dehydrogenase & 1.6 \\
\hline Rv2309A & & Hypothetical protein & 2.0 \\
\hline Rv2310 & & Possible excisionase & 2.0 \\
\hline Rv2345 & & Possible conserved transmembrane protein & 2.0 \\
\hline Rv2346c & $e s x O$ & Putative ESAT-6 like protein & 2.0 \\
\hline $\operatorname{Rv} 2350 c$ & plcB & Probable membrane-associated phospholipase C 2 & 1.7 \\
\hline Rv2448c & vals & Probable valyl-tRNA synthase protein & 1.9 \\
\hline $\operatorname{Rv} 2449 c$ & & Conserved hypothetical protein & 1.9 \\
\hline Rv2504c & $\operatorname{sco} A$ & Probable succinyl-coA:3-ketoacid-coenzyme A transferase & 1.5 \\
\hline Rv2505c & fadD35 & Probable fatty-acid-coA ligase & 1.5 \\
\hline $\operatorname{Rv} 2739 c$ & & Possible alanine-rich transferase & 1.9 \\
\hline $\operatorname{Rv} 2812$ & & Probable transposase & 2.5 \\
\hline Rv2956 & & Conserved hypothetical protein & 2.0 \\
\hline Rv2957 & & Possible glycosyl transferase & 2.0 \\
\hline Rv2972c & & Possible conserved membrane or exported protein & 1.7 \\
\hline Rv2973c & $\operatorname{rec} G$ & Probable ATP-dependent DNA helicase & 1.7 \\
\hline
\end{tabular}


Table 1. cont.

\begin{tabular}{|c|c|c|c|}
\hline $\operatorname{Rv} 3263$ & & Probable DNA methylase & 2.3 \\
\hline Rv3304 & & Conserved hypothetical protein & 2.4 \\
\hline Rv3334 & & Probable transcriptional regulatory protein & 1.8 \\
\hline Rv3342 & & Possible methyltransferase & 1.9 \\
\hline Rv3473c & bpoA & Possible peroxidase & 1.7 \\
\hline Rv3498c & $m c e 4 B$ & MCE-family protein & 2.0 \\
\hline Rv3560c & fadE30 & Probable acyl-coA dehydrogenase & 1.8 \\
\hline Rv3725 & & Possible oxidoreductase & 1.6 \\
\hline Rv3771c & & Conserved hypothetical protein & 1.5 \\
\hline Rv3772 & hisC2 & Probable histidinol-phosphate aminotransferase & 1.5 \\
\hline
\end{tabular}

has been reported (Clemens \& Horwitz, 1995; Piddington et al., 2000); however, their response to oxygen- and $\mathrm{pH}$ induced stress is unclear. To evaluate the influence of an acidic $\mathrm{pH}$ and low oxygen levels on gene expression in $M$. tuberculosis $\mathrm{H} 37 \mathrm{Rv}$, bacilli were cultured under the following conditions: normal conditions ( $\mathrm{pH} 7.2$ and $21 \% \mathrm{O}_{2}$ ), normal $\mathrm{pH}$ with hypoxia ( $\mathrm{pH} 7.2$ and $13 \%$ $\left.\mathrm{O}_{2}\right)$, normal pH with anoxia $\left(\mathrm{pH} 7.2\right.$ and $\left.0 \% \mathrm{O}_{2}\right)$, mildly acidic $\mathrm{pH}$ with hypoxia ( $\mathrm{pH} 6.0$ and $13 \% \mathrm{O}_{2}$ ) and mildly acidic $\mathrm{pH}$ with anoxia ( $\mathrm{pH} 6.0$ and $0 \% \mathrm{O}_{2}$ ). Mycobacterial RNA extracted from the five cultures grown under the different conditions was then reverse transcribed and hybridized with the CAL. The CAL-binding cDNAs were amplified by PCR and used as probes for dot blot hybridization with the $M$. tuberculosis H37Rv library (Fig. 1, step 2).

\section{Identification of differentially expressed genes under mild acidic and hypoxic conditions}

Those genes that were differentially expressed under acidic and/or hypoxic conditions were identified by analysing the differential hybridization patterns of the probes prepared from the total RNA and CAL hybridization (Fig. 2). The fold changes were calculated in comparison to the results from a normal culture $\left(\mathrm{pH} 7.2,21 \% \mathrm{O}_{2}\right)$. We then selected the clones that showed at least a 1.5-fold change in expression in the five different cultures for further analysis.

The sequences of the differentially expressed clones were analysed using the BLAST program from the National Center for Biotechnology Information (www.ncbi.nlm.nih.gov). All sequences with at least $100 \mathrm{bp}$ of alignment with the $M$. tuberculosis genome were considered to be specifically amplified.

\section{Bioinformatic analysis of induced and repressed genes}

Of the 144 genes identified by screening the M. tuberculosis H37Rv library, 101 were induced under acidic and/or hypoxic conditions, while 43 were repressed. Among the 101 induced genes, 71 were induced by both an acidic $\mathrm{pH}$ and hypoxia (Table 1), whereas 14 were induced only by hypoxia (see Supplementary Table S2 available with the online journal). Sixteen genes were induced by an acidic $\mathrm{pH}$ condition (see Supplementary Table S2 available with the online journal). Among the 43 downregulated genes, 8 were repressed by both an acidic $\mathrm{pH}$ and hypoxia (Table 2),

Table 2. M. tuberculosis H37Rv genes with decreased expression under mild acidic and hypoxic conditions

\begin{tabular}{|c|c|c|c|}
\hline Locus & Annotated gene & Product & Fold change \\
\hline Rv0456A & & Conserved hypothetical protein & -1.4 \\
\hline Rv0457c & & Probable peptidase & -1.4 \\
\hline Rv0556 & & Probable conserved transmembrane protein & -1.5 \\
\hline Rv1393c & & Probable monoxygenase & -2.0 \\
\hline Rv2576c & & Possible conserved membrane protein & -1.9 \\
\hline Rv2577 & & Conserved hypothetical protein & -1.9 \\
\hline Rv3249c & & Possible transcriptional regulatory protein & -1.8 \\
\hline Rv3250c & $\operatorname{rubB}$ & Probable rubredoxin & -1.8 \\
\hline
\end{tabular}


whereas 33 were repressed only by hypoxia and 2 genes were repressed only by acidic $\mathrm{pH}$ condition (see Supplementary Table S3 available with the online journal). The induced and repressed genes were then subjected to bioinformatic analysis.

To characterize the roles of the differentially expressed genes, the genes were divided into functional categories based on information obtained from the Clusters of Orthologous Groups of proteins (COGs) website (http:// ncbi.nlm.nih.gov/COG/; Table 3). Interestingly, the number of induced genes was greater than the number of repressed genes, even though $M$. tuberculosis was not actively growing under either condition.

Those 71 genes with a mean-fold change in expression $>1.5$ under acidic $\mathrm{pH}$ and hypoxic conditions in comparison to expression in a normal culture $(\mathrm{pH} 7.2$, $21 \% \mathrm{O}_{2}$ ) are listed in Table 1. $R v 1181$, also known as pks4, was the gene most highly induced by an acidic $\mathrm{pH}$ and hypoxia. This gene encodes a polyketide $\beta$-ketoacyl synthase involved in the biosynthesis of cell wall lipid (Dubey et al., 2002). The second most highly induced gene was Rv0696, which encodes a membrane sugar transferase that functions in cell wall biosynthesis. Rv0211 (pckA), which encodes phosphoenolpyruvate carboxykinase required for growth on fatty acids as the major carbon source (Liu et al., 2003), was also induced under acidic and hypoxic conditions. Rv2350c ( plcB), which encodes a phospholipase involved in the virulence of $M$. tuberculosis (Raynaud et al., 2002), was upregulated under acidic and hypoxic conditions. It has been proposed that lipids serve as the carbon source for growing bacteria. The storage of lipids in vivo may therefore be crucial to the survival of the bacteria and allow them to adapt to the host cell environment.

Under conditions of oxygen stress, the most highly induced gene was $R v 2934$, also known as $p p s D$. The protein encoded by $p p s D$ is a phenolpthiocerol synthesis type-I polyketide synthase, which is involved in the synthesis of the lipid core common to phthiocerol dimycocerosates and phenolglycolipids, which have been studied because of their key roles in the pathogenesis of $\mathrm{TB}$ and tubercle bacillus-host interactions (Reed et al., 2004).

Rv0006, also known as gyrA, was the most highly induced gene under acidic conditions. Rv2456c, which encodes a probable conserved integral membrane transport protein, and $R v 3731$, which encodes a DNA ligase required for the growth of $M$. tuberculosis, were induced under acidic $\mathrm{pH}$ conditions. Also, Rv1750c ( $f a d D 1$ ), which encodes fatty acid-CoA ligase, which catalyses the formation of fatty acyl-CoA (Weimar et al., 2002), was highly induced under $\mathrm{pH}$ stress.

Forty-three genes were significantly downregulated by acidic $\mathrm{pH}$ and/or hypoxia, including five genes involved in energy production and conversion. Among these five

Table 3. List of functional categories of 71 induced and 8 repressed genes identified in this study

Genes with a mean fold change in expression of $>1.5$ or $<0.5$ are classified.

\begin{tabular}{|c|c|c|c|}
\hline Functional category & $\begin{array}{l}\text { No. of genes in } \\
\mathrm{H} 37 \mathrm{Rv} \text { genome }\end{array}$ & $\begin{array}{l}\text { No. of induced } \\
\text { genes in library }\end{array}$ & $\begin{array}{l}\text { No. of repressed } \\
\text { genes in library }\end{array}$ \\
\hline Translation & 121 & 2 & 0 \\
\hline RNA processing and modification & 1 & 0 & 0 \\
\hline Transcription & 200 & 1 & 1 \\
\hline Replication, recombination and repair & 204 & 3 & 0 \\
\hline Cell cycle control, mitosis and meiosis & 40 & 1 & 0 \\
\hline Defence mechanisms & 39 & 0 & 0 \\
\hline Signal transduction mechanisms & 117 & 0 & 1 \\
\hline Cell wall/membrane biogenesis & 112 & 4 & 0 \\
\hline Cell motility & 11 & 1 & 0 \\
\hline Intracellular trafficking and secretion & 21 & 0 & 0 \\
\hline Post-translational modification, protein turnover, chaperones & 98 & 4 & 0 \\
\hline Energy production and conversion & 210 & 7 & 1 \\
\hline Carbohydrate transport and metabolism & 111 & 4 & 0 \\
\hline Amino acid transport and metabolism & 184 & 2 & 1 \\
\hline Nucleotide transport and metabolism & 64 & 2 & 0 \\
\hline Coenzyme transport and metabolism & 121 & 4 & 0 \\
\hline Lipid transport and metabolism & 257 & 5 & 0 \\
\hline Inorganic ion transport and metabolism & 124 & 3 & 1 \\
\hline Secondary metabolites biosynthesis, transport and catabolism & 234 & 5 & 0 \\
\hline General function prediction only & 436 & 5 & 1 \\
\hline Function unknown & 208 & 2 & 0 \\
\hline Not in COGs website & 1480 & 16 & 2 \\
\hline
\end{tabular}


genes one gene was downregulated by acidic $\mathrm{pH}$ and hypoxia, and four genes were downregulated by hypoxia only. It is possible that a slow metabolism occurs in regard to energy production or conversion under limited oxygen supply. The rubB gene, which encodes rubredoxin, was downregulated, as were $s u c D$, which encodes succinyl-CoA synthetase, TCA cycle enzyme, and $p d h B$ and $p d h C$, which encode subunits of the pyruvate dehydrogenase (PDH) enzyme complex, which functions to convert pyruvate to acetyl-CoA and $\mathrm{CO}_{2}$. During the chronic phase of infection, M. tuberculosis switches its metabolism to use fatty acids as its major carbon and energy source (McKinney et al., 2000; Timm et al., 2003). Under these conditions, glycolysis is decreased and $\mathrm{PDH}$ activity is not essential. $p c a$, which encodes pyruvate carboxylase, was repressed under hypoxic conditions. Those eight genes with a mean fold change in expression $<1.5$ under acidic $\mathrm{pH}$ and hypoxic condition are listed in Table 2.

The differential expression of these genes at the level of transcription under each set of conditions was confirmed by RT-PCR using $r p o B$ as an internal standard. As shown in Fig. 3, a single band of the expected molecular size was detected for each of the transcripts from $M$. tuberculosis H37Rv. rpoB varied little during the bacterial growth cycle in vitro. Based on the intensities of the bands, the results are expressed as the fold induction relative to the control value of normal culture $\left(\mathrm{pH} 7.2,21 \% \mathrm{O}_{2}\right)$.

Six induced and three repressed genes involved in the TCA cycle and the glyoxylate cycle pathways, and cell wall lipid synthesis, were identified in this study. M. tuberculosis can survive in macrophages; thus, it must assimilate carbon and produce energy in the phagosome (Höner zu Bentrup \& Russell, 2001). Schnappinger et al. (2003) demonstrated that $M$. tuberculosis switched its carbon source in vitro from glucose and glycerol to fatty acids in the phagosome. These fatty acids may be derived from triglycerides by lipase. The breakdown products of fatty acids are metabolized via the citric acid and glyoxylate cycles, as suggested by the induction of genes such as fadD1. The induction of $p c k A$ suggests that fatty acids are in part converted to sugars via gluconeogenesis. These data support the view that $M$. tuberculosis might use glyoxylate bypass through degradation of fatty acid during metabolism under conditions of acidic $\mathrm{pH}$ and hypoxia. The glyoxylate cycle bypasses the steps in which $\mathrm{CO}_{2}$ is generated by the TCA cycle and allows acetyl-CoA and glyoxylate to form succinate, a precursor for the synthesis of sugars. Lipids are a source of acetyl-CoA through the degradation of fatty acids via the $\beta$ oxidation cycle. Consequently, the glyoxylate bypass allows $M$. tuberculosis and other bacteria to synthesize carbohydrates from fatty acids, and it supplies the intermediates necessary to support the TCA cycle. This is of obvious importance when fatty acids are the main source of carbon and energy, as has been suggested for M. tuberculosis and Mycobacterium leprae in chronically infected tissues (Bloch \& Segal, 1956; Wheeler \& Ratledge, 1988).
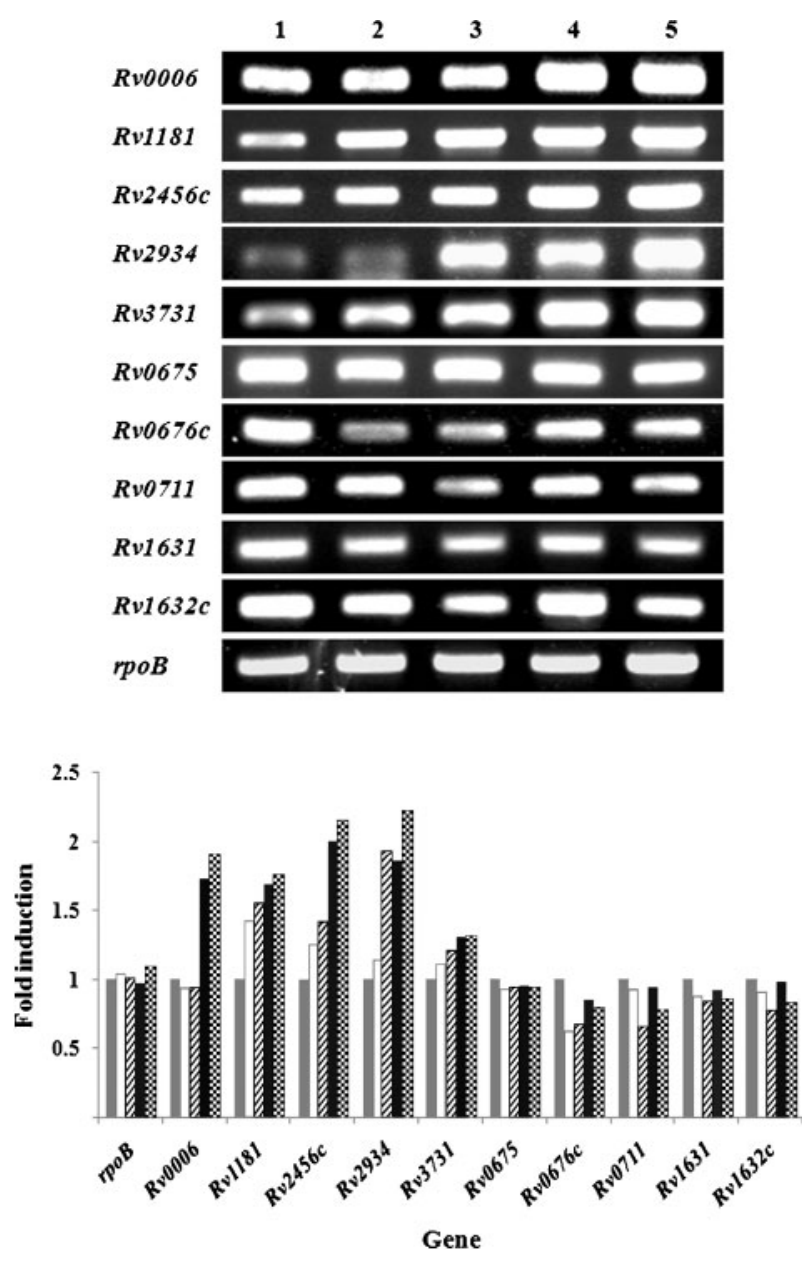

Fig. 3. RT-PCR analysis of the induced and repressed genes of M. tuberculosis H37Rv cultured under an in vitro dormancy model. The five induced and five repressed genes were selected according to their order of increase and decrease in fold change. The transcription level of each $M$. tuberculosis H37Rv gene cultured at different oxygen atmospheres with normal or acidic $\mathrm{pH}$ was analysed by RT-PCR. 1, normal atmosphere with $\mathrm{pH} 7.2$ (grey bars); 2, hypoxic atmosphere with pH 7.2 (white bars); 3, hypoxic atmosphere with $\mathrm{pH} 6.0$ (hatched bars); 4, anoxic atmosphere with $\mathrm{pH} 7.2$ (black bars); 5, anoxic atmosphere with $\mathrm{pH} 6.0$ (bars with spots).

Furthermore, the upregulation of genes such as pks4, $R v 0696$, plcB and $p p s D$ involved in the synthesis of selected cell wall lipids using fatty acids was also apparent during survival under acidic $\mathrm{pH}$ and hypoxia. Therefore, $M$. tuberculosis might avoid producing acetyl-CoA from pyruvate by downregulation of genes such as $p d h B$ and $p d h C$ and prefer glyoxylate bypass through degradation of fatty acid in metabolism.

The abundance of genes encoding enzymes involved in fatty acid degradation supports the idea that M. tuberculosis uses host lipids to support its growth in vivo. Bloch \& Segal (1956) showed that bacteria grown in vitro had a preference 
for carbohydrates, whereas bacteria grown in vivo preferred fatty acids. M. tuberculosis probably feeds on the lipid-rich host-cell debris in mature granulomas and on degraded fatty acids in the endosomal milieu of nascent granulomas. In this setting, fatty acid biosynthesis is repressed and cell wall constituents such as mycolic acids arise preferentially by the elongation of internalized fatty acids, as has been shown for other mycobacterial species (Bloch \& Segal, 1956; Wheeler et al., 1990, 1991).

The limited growth of M. tuberculosis H37Rv under acidic $\mathrm{pH}$ and oxygen stress parallels the survival of $M$. tuberculosis in the acidic vacuoles of macrophages. The identification of $M$. tuberculosis genes that contribute to bacterial survival will ultimately enhance the development of new treatments for the latent TB patient.

\section{ACKNOWLEDGEMENTS}

This study was supported by a grant from the Korea Health 21 R\&D project, Ministry of Health and Welfare, Republic of Korea (01-PJ10PG6-01GM03-002), the Chungnam National University Hospital Research Fund, 2005, and the Korea Science \& Engineering Foundation through the Infection Signaling Network Research Center (R13-2007-020-01000-0) at Chungnam National University.

\section{REFERENCES}

Alland, D., Kramnik, I., Weisbrod, T. R., Otsubo, L., Cerny, R., Miller, L. P., Jacobs, W. R., Jr \& Bloom, B. R. (1998). Identification of differentially expressed mRNA in prokaryotic organisms by customized amplification libraries (DECAL): the effect of isoniazid on gene expression in Mycobacterium tuberculosis. Proc Natl Acad Sci U S A 95, 13227-13232.

Belisle, J. T. \& Sonnenberg, M. G. (1998). Isolation of genomic DNA from mycobacteria. Methods Mol Biol 101, 31-44.

Bloch, H. \& Segal, W. (1956). Biochemical differentiation of Mycobacterium tuberculosis grown in vivo and in vitro. J Bacteriol 72, 132-141.

Clemens, D. L. \& Horwitz, M. A. (1995). Characterization of the Mycobacterium tuberculosis phagosome and evidence that phagosomal maturation is inhibited. J Exp Med 181, 257-270.

Dubey, V. S., Sirakova, T. D. \& Kolattukudy, P. E. (2002). Disruption of $m s l 3$ abolishes the synthesis of mycolipanoic and mycolipenic acids required for polyacyltrehalose synthesis in Mycobacterium tuberculosis H37Rv and causes cell aggregation. Mol Microbiol 45, 1451-1459.

Höner zu Bentrup, K. \& Russell, D. G. (2001). Mycobacterial persistence: adaptation to a changing environment. Trends Microbiol 9, 597-605.

Kochi, A. (1991). The global tuberculosis situation and the new control strategy of the World Health Organization. Tubercle 72, 1-6.

Koul, A., Herget, T., Klebl, B. \& Ullrich, A. (2004). Interplay between mycobacteria and host signalling pathways. Nat Rev Microbiol 2, 189-202.

Liu, K., Yu, J. \& Russell, D. G. (2003). pckA-deficient Mycobacterium bovis BCG shows attenuated virulence in mice and in macrophages. Microbiology 149, 1829-1835.

McKinney, J. D., Höner zu Bentrup, K., Muñoz-Elias, E. J., Miczak, A., Chen, B., Chan, W. T., Swenson, D., Sacchettini, J. C., Jacobs, W. R., Jr \& Russell, D. G. (2000). Persistence of Mycobacterium tuberculosis in macrophages and mice requires the glyoxylate shunt enzyme isocitrate lyase. Nature 406, 735-738.

Mustafa Abu, S. \& Al-Attiyah, R. (2003). Tuberculosis: looking beyond BCG vaccines. J Postgrad Med 49, 134-140.

Payton, M. \& Pinter, K. (1999). A rapid novel method for the extraction of RNA from wild-type and genetically modified kanamycin resistant mycobacteria. FEMS Microbiol Lett 180, 141-146.

Piddington, D. L., Kashkouli, A. \& Buchmeier, N. A. (2000). Growth of Mycobacterium tuberculosis in a defined medium is very restricted by acid $\mathrm{pH}$ and $\mathrm{Mg}^{2+}$ levels. Infect Immun 68, 4518-4522.

Raynaud, C., Guilhot, C., Rauzier, J., Bordat, Y., Pelicic, V., Manganelli, R., Smith, I., Gicquel, B. \& Jackson, M. (2002). Phospholipases $\mathrm{C}$ are involved in the virulence of Mycobacterium tuberculosis. Mol Microbiol 45, 203-217.

Reed, M. B., Domenech, P., Manca, C., Su, H., Barczak, A. K., Kreiswirth, B. N., Kaplan, G. \& Barry, C. E., III (2004). A glycolipid of hypervirulent tuberculosis strains that inhibits the innate immune response. Nature 431, 84-87.

Russell, D. G. (2001). Mycobacterium tuberculosis: here today, and here tomorrow. Nat Rev Mol Cell Biol 2, 569-577.

Salkin, D. \& Wayne, L. G. (1956). The bacteriology of resected tuberculous pulmonary lesions. I. The effect of interval between reversal of infectiousness and subsequent surgery. Am Rev Tuberc 74, 376-387.

Sambrook, J. \& Russel, D. R. (2001). Molecular Cloning; a Laboratory Manual, 3rd edn. Cold Spring Harbor, NY: Cold Spring Harbor Laboratory.

Schnappinger, D., Ehrt, S., Voskuil, M. I., Liu, Y., Mangan, J. A., Monahan, I. M., Dolganov, G., Efron, B., Butcher, P. D. \& other authors (2003). Transcriptional adaptation of Mycobacterium tuberculosis within macrophages: insights into the phagosomal environment. J Exp Med 198, 693-704.

Timm, J., Post, F. A., Bekker, L. G., Walther, G. B., Wainwright, H. C., Manganelli, R., Chan, W. T., Tsenova, L., Gold, B. \& other authors (2003). Differential expression of iron-, carbon-, and oxygenresponsive mycobacterial genes in the lungs of chronically infected mice and tuberculosis patients. Proc Natl Acad Sci U S A 100, 1432114326.

Wayne, L. G. (1994). Dormancy of Mycobacterium tuberculosis and latency of disease. Eur J Clin Microbiol Infect Dis 13, 908-914.

Wayne, L. G. \& Hayes, L. G. (1996). An in vitro model for sequential study of shiftdown of Mycobacterium tuberculosis through two stages of nonreplicating persistence. Infect Immun 64, 2062-2069.

Weimar, J. D., DiRusso, C. C., Delio, R. \& Black, P. N. (2002). Functional role of fatty acyl-coenzyme A synthetase in the transmembrane movement and activation of exogenous long-chain fatty acids. Amino acid residues within the ATP/AMP signature motif of Escherichia coli FadD are required for enzyme activity and fatty acid transport. J Biol Chem 277, 29369-29376.

Wheeler, P. R. \& Ratledge, C. (1988). Use of carbon sources for lipid biosynthesis in Mycobacterium leprae: a comparison with other pathogenic mycobacteria. J Gen Microbiol 134, 2111-2121.

Wheeler, P. R., Bulmer, K. \& Ratledge, C. (1990). Enzymes for biosynthesis de novo and elongation of fatty acids in mycobacteria grown in host cells: is Mycobacterium leprae competent in fatty acid biosynthesis? J Gen Microbiol 136, 211-217.

Wheeler, P. R., Bulmer, K. \& Ratledge, C. (1991). Fatty acid oxidation and the $\beta$-oxidation complex in Mycobacterium leprae and two axenically cultivable mycobacteria that are pathogens. J Gen Microbiol 137, 885-893. 